$\underline{\text { Review Article }}$

\title{
A REVIEW ON THE PHARMACOLOGICAL AND TRADITIONAL PROPERTIES OF MIMOSA PUDICA
}

\author{
NDANUSA ABDULLAHI HASSAN ${ }^{1}$, ROHINI KARUNAKARAN ${ }^{2 *}$, SULEIMAN ABDULMUMIN ${ }^{3}$ \\ ${ }^{1}$ Departmentof Biology, Faculty of Science, Universiti Brunei Darussalam, Brunei Darussalam, ${ }^{2}$ Unit of Biochemistry, Faculty of Medicine, AIMST \\ University, Semeling, Bedong, Malaysia, ${ }^{3}$ Department of Biological science, Faculty of Science, Nigerian Defense Academy Kaduna, Nigerian \\ Email: ndanusabb@gmail.com
}

Received: 24 Oct 2018 Revised and Accepted: 04 Feb 2019

\begin{abstract}
Consumption of fruits and vegetables fight against oxidative damage by inhibiting or reducing free radicals and reactive oxygen species. Mimosa pudica is a perennial herb and belongs to the family Fabaceae. Epidemiological studies have shown that M. pudica contains metabolites such as phenols and flavonoid compounds which possess pharmacological properties such as antidiabetic, antimicrobial, antiulcer, antidepressants and anti-inflammatory. Ecological studies have shown that M. pudica grows in all types of soil which can survive in soil with low nutrient concentration. It usually requires disturbed soil to establish itself. It is commonly seen in the wastelands and along roadsides, which is an ethnomedical plant that may be used in managing various types of disease. Valuable information and literature on M. pudica are analysed and consulted using a different database such as Google Scholar, Google, Science Direct, Web of Science, Academic Journals and Pubmed. This review article summarises the pharmacological properties of $M$. pudica.
\end{abstract}

Keywords: Mimosa pudica, Reactive oxygen species, Anti-diabetic, Anti-inflammatory, Antimicrobial

(c) 2019 The Authors. Published by Innovare Academic Sciences Pvt Ltd. This is an open access article under the CC BY license (http://creativecommons.org/licenses/by/4.0/) DOI: http://dx.doi.org/10.22159/ijpps.2019v11i3.30452

\section{INTRODUCTION}

Consumption of fruits and vegetables fight against oxidative damage by inhibiting or reducing free radicals and reactive oxygen species (ROS) $[1,2]$. Many plants including vegetables and fruits contain natural antioxidants that can combat oxidative stress and play a crucial part in the chemoprevention of diseases that have their aetiology and pathophysiology in ROS [3, 4]. These properties are believed to be attributed to the antioxidants like flavonoids, lycopene, carotenoids, $\beta$-carotene and phenolic compounds. Herbs have been a source of medicinal agents for centuries and are an excellent source of nutraceuticals. Herbal therapy is mainly used to treat cardiovascular problems, liver disorders, central nervous system, digestive and metabolic disorders $[1,5]$. Researchers are currently focusing on the medicinal properties of plant products with bio-active potentials which have good therapeutic characteristics. Recent studies have been focused on the pharmacological actions of $M$. pudica (fig. 1) which have effective anti-diabetic, antitoxin, antihepatotoxic, antioxidant activities [4, 5].

M. pudica, also known as Lajjalu in Ayurveda, is widely used as an antidepressant and anti-asthmatic in the treatment of various kind of ailments [6, 7]. Epidemiological studies have also shown that $M$. pudica contains metabolites such as phenols and flavonoid compounds which possess anticancer and antidiabetic properties [8]. Research also has been demonstrated that different parts of this plant are widely used in the treatment of multiple diseases $[9,10]$. This article focusses on the pharmacological and traditional properties of M. pudica [11, 12].

\section{Ecology}

M. pudica grows in all types of soil; it can survive in soil with low nutrient concentration. It usually requires disturbed soil to establish itself. Frequent burning may encourage its spread in pastures. The plant does shade sensitive and does not grow under forest canopies. Carbon disulfide is produced by the root which discerning inhibit colonization of the rhizosphere by mycorrhizal and pathogenic fungi. This plant grows by the roadsides or area disturbed by constructions; it usually grows as a single plant or in tangled thickets. It also grows near sea level up to $1,300 \mathrm{~m}$ in elevation with annual precipitations from about 1000 to $200 \mathrm{~mm}[12,13]$

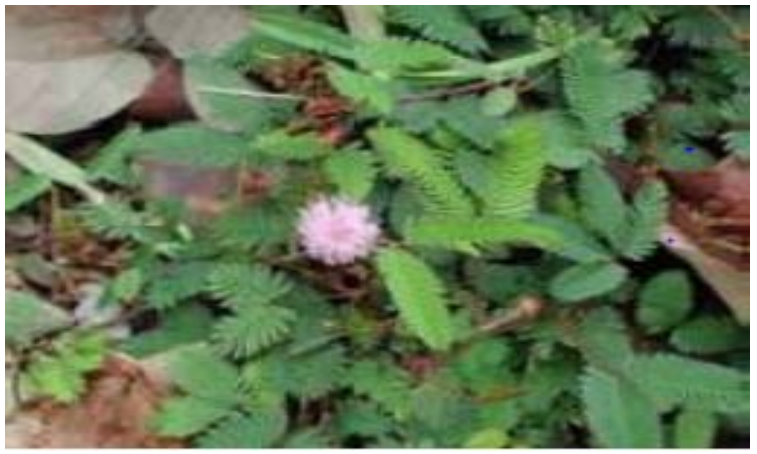

Fig. 1: Mimosa pudica [5]

\section{Constituents}

M. pudica stem and root tend to contain alkaloids the adrenaline-like substance has been identified in the leaves. The roots of the plant are also said to contain tannins, and the seeds' mucilage is composed of D-xylose and d-glucuronic acid [14]. The chromatographic procedure revealed that petroleum fraction contains mainly amino acids, phytosterol, flavonoids, and alkaloids. The essential oils and fatty acid are present in the benzene extracts, and the chloroform extracts showed the presence of alkaloids [15]. The chemical constituents of M. pudica [15] are listed in table 1 and fig. 2 .

\section{Bending movement of $M$. pudica}

M. pudica is said to have a unique motor organ which can either be pulvini or epinastic. Both processes involve the increase in the rate of membrane water transport which is facilitated by aquaporin which has been shown in many cases. Tonoplast and plasma membrane help in localizing aquaporins to seismonastic leaf movement in M. pudica and has been analysed [16]. The bending movement of $M$. pudica pulvinus causes a rapid change in volume of the abaxial motor cell in response to various environmental stimuli. The bending movement of $M$. pudica is delayed by treatment with actin affecting reagent and calcium channels inhibitors. The filament 
of actin found in motor cells is a fragment in response to electrical stimulation. The study has shown that increased in levels of calcium is due to the depolymerization of the actin cytoskeleton in pulvinus motor cells in response to the electrical signals [17].

Table 1: Chemical constituent of $M$. pudica

\begin{tabular}{ll}
\hline Parts & Chemical constituents \\
\hline Stem & Mimosine, 5-MeO-DMT (2), $\beta$-[N-(3-hydroxypyridone-4)]- $\alpha$-aminopropionic acid. \\
Root & $\begin{array}{l}\text { Mimosine, alkaloids, amino acids, glycoside, fatty acid, flavonoid, phytosterol and tannins. crocetin, ascorbic acid, D-glucuronic acid, } \\
\text { linoleic acid, D-xylose and B-sitosterols }\end{array}$ \\
Leaves & $\begin{array}{l}\text { Tyrosin, vitexin, nor-epinephrine, d-pinitol, b-sitosterol, alkaloids-mimosine, terpenoids, flavonoids, glycosides, alkaloids, phenols, } \\
\text { tannins, saponins, and coumarins, polyunsaturated fatty acid, sphingosine, adrenalin, 5-MeO-DMT (2), 5,7,3',4'-tetrahydroxy-6-C-[B-D- } \\
\text { apiose-(1)4)]- } \beta \text {-D-glycopyranosyl flavone (7). }\end{array}$ \\
\hline
\end{tabular}<smiles>NCC(O)c1ccc(O)c(O)c1</smiles>

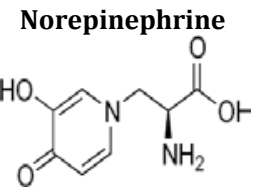

L-mimosine<smiles>COc1ccc2[nH]cc(CCN(C)C)c2c1</smiles>

5-Me0-DMT<smiles>Cc1cc(C2CC(=O)c3c(cc(O)c(C4O[C@H](CO)[C@@H](O)[C@H](O)C4O)c3O)O2)ccc1O</smiles>

5, 7, 3', 4'-tetrahydroxyl-6-C-beta-D-glucopyranosyl flavones<smiles>O=c1cc(-c2ccc(O)cc2)oc2cc(O)c([C@@H]3O[C@H](CO)[C@@H](O)[C@H](O)[C@H]3O)c(O)c12</smiles>

Isovitexin<smiles>O=C[C@H](O)[C@H](O)[C@H](O)CO</smiles>

d-xylose<smiles>O=C1O[C@H]([C@@H](O)CO)C(O)=C1O</smiles>

$\mathrm{HO}$<smiles>CC(C)(C)Oc1cc(O)c(O)c(C(=O)O)c1</smiles>

Gallic acid

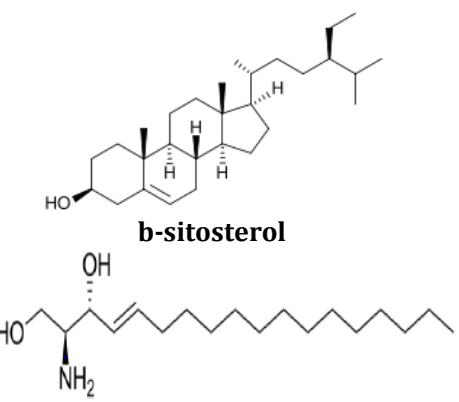

Sphingosine<smiles>O=c1cc(-c2ccc(O)c(O)c2)oc2cc(O)c(C3OC(CO)C(O)C(O)C3O)c(O)c12</smiles>

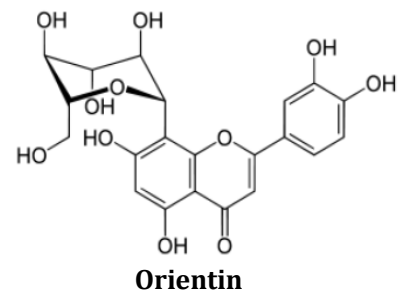<smiles>N[C@@H](Cc1ccc(O)cc1)C(=O)O</smiles>

d-glucuronic acid<smiles>CC=C(C)C=CC=CC=CC=C(C)C=CC=C(C)C(=O)O</smiles>

Crocetin

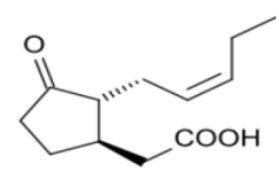

Jasmonic acid

Fig. 2: Structure of different types of $M$. pudica phytoconstituents [15] 


\section{Traditional uses of $M$. pudica}

The root of M. pudica is declared to be bitter, cooling vulnerary, acrid, alexipharmic and used in the treatment of various types of diseases such as leprosy, dysentery, inflammation and many more by Ayurveda $[12,13]$. The Unani Healthcare system uses its root in the treatment of disease arising from blood impurities and bile, bilious fevers, piles and jaundice. It also reduces a toothache by the decoction of root with water. It is also found to arrest bleeding and fasten the wound healing process. It is also used in herbal preparation for a gynaecological disorder [13]. It is beneficial in the treatment of diarrhoea, amoebic dysentery and has been researched to have medicinal properties to cure skin diseases. Studies have shown that it is also used to treat neurological problems [18]. The flower, root, stem, leave, and the fruits are used as medicines in the traditional health care system different parts of the plants are used in India for long for treatment of various kind of ailments. Researchers have indicated that M. pudica is used to relax the mind, relieves depression, mental distress, irritability and amnesia. It is also used to enhance mood and improves the circulation of blood. It also promotes healthy cell growth and prevents baldness. In western medicine, its root was used for the treatment of insomnia, irritability, premenstrual syndrome haemorrhoids and whooping cough [19].

\section{Pharmacological effects}

\section{Anti-helminthic activity}

Helminths have been a foremost degenerative disease disturbing large percentage of the world and pose an enormous threat to public health in the developing countries which contribute to various ailments such as malnutrition, anaemia, eosinophilia and pneumonia. The parasite of helminths mainly subsists in the human body in the intestinal tract. Resistance in helminths against conventional anthelmintics is a leading problem in the treatment of the diseases. M. pudica has been reported to have anti-helminths activity. Another study by Pratap et al. shows the anti-helminthic activity of aqueous leaves extracts of M. pudica. Albendazole was used as a standard drug, prepared in four different concentration of $20,40,60$ and $80 \mathrm{mg} / \mathrm{ml}$ which was further dissolved in normal saline. The earthworm $P$. posthuman was divided into five groups consisting of two equal sizes and then released into $30 \mathrm{ml}$ of the experimental formulations. Freshly prepared a standard drug and Aqueous extracts of $M$. pudica was used for the experiment. The paralysis time was recorded when there were no movements observed, and death time was recorded in minutes. The aqueous extracts showed considerable anti-helminthic activity which varies with different concentration [20,21].

\section{Antihepatotoxic activity}

Research has shown that the leaves of M. pudica possess hepatoprotective activity, in a study conducted involving $14 \mathrm{~d}$ administration of ethanolic leave extracts to Wistar rats treated with carbon tetrachloride at a dose of $200 \mathrm{mg} / \mathrm{kg} \mathrm{p}$. o. This study also shows that a high level of serum SGPT, SGOT, ALP and total bilirubin, due to CCL4 (carbon tetrachloride) treatment, were found to be restored close to normal on therapy with $M$. pudica. The study revealed the hepatoprotective effects of $M$. pudica due to antioxidant properties. Another research by Ayan et al. evaluated the hepatoprotective activity of ethanolic leave extracts of $M$. pudica. Wister rats of both sexes were used weighing between 150-200g, the animals were acclimatised under standard laboratory protocols. Carbon tetrachloride was used to induce liver toxicity in the experimental rats subcutaneously at a dose of $1 \mathrm{ml} / \mathrm{kg} \mathrm{b}$. w for one week. The animals were divided into five groups of six animal, and Silymarin was used as a standard which was administered for one week at a dose of $100 \mathrm{mg} / \mathrm{kg} \mathrm{p}$. o. M. pudica was administered to a different group at a dose of $400 \mathrm{mg} / \mathrm{kg} \mathrm{p}$. o for one week. Blood was collected at the end of the experiment, and biochemical parameters were estimated such as Total Bilirubin (TB), Direct Bilirubin (DB), Alkaline Phosphatase (ALP), Serum Glutamate Pyruvate Transaminase (SGPT) and Serum glutamate oxaloacetate transaminase (SGPT). The results of the CCL4 induced hepatotoxicity were estimated, and the group which received ethanolic leave extracts of M. pudica at a dose of $400 \mathrm{mg} / \mathrm{kg}$ and the standard drug
Silymarin showed a significant decrease in the elevated levels of SGPT, SGOT, ALP, TB, and DB. This study shows the hepatoprotective effects of M. pudica [22, 23]

\section{Wound healing activity}

Damage in living tissue caused by a cut, blow, or other impacts is termed as a wound. M. pudica chloroform extract possess wound healing activity at a dose of $200 \mathrm{mg} / \mathrm{kg}$ in $5 \%$ ointment of the leaf extracts. Wound healing is a natural process initiated by trauma and often terminated by scar formation; the wound healing activity was reported to be performed by using excision and incision wound models [10]. Different studies have also shown that both methanolic and aqueous extracts of $M$. pudica in simple ointment base at a different concentration of $0.5 \%(\mathrm{w} / \mathrm{w}), 1 \%(\mathrm{w} / \mathrm{w})$ and $2 \%(\mathrm{w} / \mathrm{w})$ possess wound healing activity. Three different types of models in rats were used, which are excision, incision and estimation of biochemical parameters. The $2 \%(\mathrm{w} / \mathrm{w})$ methanolic and aqueous extracts exhibited significant wound healing activity probably due to phenols constituent in M. pudica. Another research by Ganesh et al. shows the wound healing activity of $M$. pudica ethanolic extracts. Mice were used for this study and were acclimatized according to standard laboratory protocols. Different doses of M. pudica 50, 100, 150 and 200 $\mathrm{mg} / \mathrm{kg} \mathrm{b}$. wt were administered to the animals for six weeks before the creation of deep dermal excision wound. At the end of the experiment the administration of $M$. pudica extracts of different concentration increased the wound contraction in a dose-dependent manner, and also reduction in wound healing time $[24,25]$.

\section{Antifertility activity}

M. pudica has been used in India for treatment of a different kind of ailment but is commonly used as an antifertility agent. The methanol extract of the root was administered orally to Swiss albino mice for twenty-one consecutive days. Phytochemical studies of the extract were carried out using thin layer chromatography (TLC) and quantitative methods [11]. Hormones responsible for reproduction (such as luteinizing hormone ( $\mathrm{LH})$, follicle-stimulating hormone (FSH), prolactin, estradiol, progesterone), oestrous cycle and many litters produced were studied in both extracts administered and control groups by using standard methods. The decrease in FSH levels in the pro-oestrous and oestrous stage in the extract administered group compared with those of the control animals indicates the disturbance of the oestrous cycle and ovulation through suppression of FSH. This study suggested that the root of $M$. pudica may possess antifertility effects as it disturbs the secretion of gonadotropin hormone and it prolongs the oestrous cycle in albino mice [10].

\section{Antidepressants}

The rate of prevalence of mental disorder patients was observed to be around 65.4/1000 population. Out of which prevalence rate for the affective disorder is estimated to be $31.2 / 1000$ populations. Antidepressants widely prescribed for depression, have significant limitations which include long time lag for therapeutic response and low response rates, which problematic for disease associated with a high rate of suicide [26]. The aqueous extract of $M$. pudica is employed to reduce depression in Mexico. This study showed the behavioural actions of $M$. pudica extract at different concentration was tested. Rats having received several dosages of aqueous extracts from M. pudica $(2.0 \mathrm{mg} / \mathrm{kg} ; 4.0 \mathrm{mg} / \mathrm{kg} ; 6.0 \mathrm{mg} / \mathrm{kg} 8.0 \mathrm{mg} / \mathrm{kg})$ or received normal saline $(0.9 \% 0.30 \mathrm{ml}$; J. P.) clomipramine, and desipramine for 30days, after which were subjected to forced swimming test and the test for differential reinforcement of low rates response at 72 second. M. pudica of different doses responsible for any possible anxiolytic action were compared with those caused by diazepam $(1.3 \mathrm{mg} / \mathrm{kg} \mathrm{J} . \mathrm{P})$ in the elevated plus maze test. Results showed that M. pudica extracts, clomipramine, desipramine reduced immobility in the forced swimming test and increased the rate of reinforcers received in the DRL-72s test, the results show that $M$. pudica produces antidepressant effects in rats [27, 28].

\section{Anxiolytic agent}

Anxiety is usually accompanied by nervous behaviour, which is an emotion categorised by an unpleasant state of inner turmoil. Anxiety is associated with muscular tension, fatigue, restlessness and 
problems in concentrations. Individuals may suffer from anxiety disorder when experienced regularly. Anxiety can be a long-term trait or short-term state $[29,30]$. M. pudica plant was used in traditional medicine in some developing countries such as Cameroon to treat anxiety disorders [31]. Anxiety disorders have severe impacts on life. Rats were used for the experiment which the anxiolytic activity was found in the animals when the EPM (elevated plus maze) was conducted and has shown that $M$. pudica reduces the percentage of closed arm entries and increases the number of entries into the percentage of entries and time in the open arms. The correlation of the increase in time spent in open arm with the rise in the number of entries supported the anxiolytic activity of the plant. It could be due to the presence of some components in the plant extracts interaction with GABA (Gamma-aminobutyric acid) receptors as an antagonist [32].

\section{Hypolipidemic activity}

Researches have utilised hat high-fat diet induced on rats' models to study the hypolipidemic action of $M$. pudica. Reports have shown that hyperlipidemia in experimental rats demonstrated an improvement in the levels of triglycerides, LDL, VLDL and cholesterol. The ethanolic extracts of $M$. pudica showed the significant hypolipidemic effect by lowering the serum of the biochemical param with a substantial reduction in the level of triglycerides, LDL, VLDL and cholesterol and increase in HDL level which was similar to the drug used as the control (lovastatin). The preliminary phytochemical of these studies show the presence of phytoconstituent such as steroid, flavonoids, glycoside alkaloids and phenolic compounds [33]. Another report by Piyapong and Ampa shows the hypolipidemic activity of $M$. pudica extracts. Albino rats weighing 150-200g were used and acclimatised according to standard laboratory protocols. The rats were divided into six groups each containing eight rats; Streptozotocin was used to induce diabetes to the animal through single intraperitoneal injection at a dose of $65 \mathrm{mg} / \mathrm{kg}$. bw. The experiment lasted for eight weeks, blood serum was collected, and biochemical parameters were analysed. The group which received $M$. pudica extracts tend to have a high level of HDL and TG, TC and LDL decrease which shows the hypolipidemic potential of M. pudica [34].

\section{Antivenom activity}

Lethality of Najakauthia venom tends to be neutralised by polyphenols found in M. pudica such as tannins. Survival of mice after $24 \mathrm{~h}$ was maintained when $M$. pudica tannins were preincubated with $N$. kaouthia venom. The group in which there was no preincubation, no protection against the effect of the toxin was observed. Commercial tannic acid was found to have lower efficiency as compared to the tannins from $M$. pudica in neutralising the lethality of $N$. kaouthia venom. Two protein spots were missing in the two-dimensional gel electrophoresis of the MTP treated animal indicating the down-regulation of the venom proteins. The result from this study shows that $M$. pudica has a better effect in neutralising the venom from $N$. kaouthia than commercial tannic acid in vitro. However, further research needs to establish that. pudica has a potential for treating $N$. kaouthia snakebites [35].

\section{Antiulcer activity}

Three different types of solvent (90\% methanol, chloroform and diethyl ether) was used for this extraction. Albino rats were used to investigate the antiulcer activity and was induced with alcohol and aspirin. The parameters obtained from this study shows that $M$. pudica has anti-ulcer properties. One hundred and $200 \mathrm{mg} / \mathrm{kg}$ dose levels of the extract and $20 \mathrm{mg} / \mathrm{kg}$ of the standard drug Ranitidine was used orally. Toxicity studies were done which they found out that the extract is safe up to a concentration of $2000 \mathrm{mg} / \mathrm{kg}$ body weight and $100 \mathrm{mg}$ which shown good activity [36, 37].

\section{Antiinflammatory activity}

The anti-inflammatory activity of $M$. pudica was investigated using male albino rats. Three different extracts of $M$. pudica was used, which are petroleum ether, ethanol and aqueous extracts. The model of the rats used was carrageenan-induced paw oedema and cotton pellet granuloma in rats. Different doses, 50,100 and $200 \mathrm{mg} / \mathrm{kg}$, of extracts, were used, and indomethacin, administered orally, was used as a standard at a concentration of $10 \mathrm{mg} / \mathrm{kg}$ Carrageenaninduced rat paw oedema was used for evaluating the reduction of oedema induced by carrageenan [38]. Another study by Nair and Bindu also investigated the anti-anti-inflammatory effect of the whole plant of $M$. pudica, in thirty albino rats of both sexes was used for the experiment. Two hundred (200) mg/kg, $400 \mathrm{mg} / \mathrm{kg}$ and 800 $\mathrm{mg} / \mathrm{kg}$ extracts of $M$. puidca was administered to three different groups, $800 \mathrm{mg} / \mathrm{kg}$ concentration has the highest percentage inhibition. The result from this recent study also shows that $M$. pudica has anti-inflammatory properties [39].

\section{Antidiabetic activity}

Diabetes is a metabolic disorder which affects people of all age, most prominent in middle age and old aged people. Various complications have been associated with diabetes such as obesity, renal dysfunction and blood lipid abnormalities. Patient self-management education and continued medical care are required to prevent acute complication and longtime effects. Anti-diabetic effect of $M$. pudica was investigated using male albino rats weighing between 150$200 \mathrm{~g}$, ethanolic extracts of $M$. pudica was administered at a dose of $500 \mathrm{mg} / \mathrm{kg}$. bw to diabetic rats induced with streptozotocin 65 $\mathrm{mg} / \mathrm{kg}$. bw. The investigation lasted for eight weeks, and the parameters obtained from the study show that $M$. pudica tend to have hypoglycemic properties on fasting blood glucose level of the experimental rats [40].

\section{Antimicrobial activity}

The preliminary phytochemical screening of the extracts shows the presence of carbohydrates, saponins flavonoids, steroids and tannins. The activity was tested against Pseudomonas aeruginosa, Bacillus subtilis, Klebsiella pneumonia, Aspergillus flavus and trichophyton at various concentration like 50, 100, $200 \mathrm{ug} / \mathrm{ml}$. The potential sensitivity of the extracts was obtained against all the microorganisms tested [41]. Another study by Chukwu et al. also shows the anti-fungal activity of the whole plant of $M$. pudica which was tested towards Aspergillus flavus and Trichophyton rubrum, three different concentration of $M$. pudica $25 \mathrm{mg} / \mathrm{ml}, 50 \mathrm{mg} / \mathrm{ml}$ and $100 \mathrm{mg} / \mathrm{ml}$ were used. Results from this study indicate that ethanolic extracts of $M$. pudica exhibited from being partially active to very active against the tested microorganism at all concentration [42-44].

\section{CONCLUSION}

This review shows that $M$. pudica is rich with different bioactive compounds that possess several pharmacological properties. $M$. pudica, commonly seen in the wastelands and along roadsides, is an ethnomedical plant that may be used in managing various types of disease. Different phytoconstituents responsible for the activities were isolated. This proves the medicinal importance of the plant. Few studies had been done on the stem, roots and flower. Therefore, advanced research studies are required to validate the therapeutic potential of the roots, stem and flower of $M$. pudica.

\section{AUTHORS CONTRIBUTIONS}

The authors contributed equally

\section{CONFLICT OF INTERESTS}

The authors report no declaration of interest

\section{REFERENCES}

1. Chattopadhyay MK. Bacterial cryoprotectants. Reson 2002;7:59-63.

2. Ndanusa AH, Rohini Karunakaran, Uma Sankar A, Khin Mar Aye. Anti-diabetic effect of Zingiber officinale on spraguedawley rats. Int J Pharma Phytol Res 2016;8:1940-3.

3. Dragan S, Nicola T, Molina R, Ursoniu S, Kumar A, Nimade S, et al. Role of multi-component functional foods in the complex treatment of patients with advanced breast cancer. Rev Med Chir Soc Med Nat Iasi 2007;111:877-84.

4. Ndanusa AH, Rohini Karunakaran, Uma Sankar A, Khin Mar Aye. Anti-inflammatory effect of Zingiber officinale on sprague dawley rats. Asian J Pharm Clin Res 2017;10:353-35. 
5. Chukwu O, Ahuchaogu A, Ukaogo P, Obike A, Echeme J. Antifungal activity of Mimosa pudica, Isolation and NMR characterization of bioactive components. Asian J Chem Sci 2017;10:1-5.

6. Rohini K, Srikumar P. Therapeutic role of coumarins and coumarin-related compounds. J Thermodyn Catal 2014;5:1-3.

7. McDonald S, Prenzler PD, Antolovich M, Robards K. Phenolic content and antioxidant activity of olive extracts. Food Chem 2001;73:73-84.

8. Zhang J, Yuan K, Zhou W, Zhou J, Yang P. Studies on the active components and antioxidant activities of the extracts of Mimosa pudica Linn. from Southern China. Pharmacogn Mag 2011;7:35.

9. Adesegun SA, Anyika NE, Adekoya TO, Essien SG. Antibacterial and antioxidant investigations of Hallealedermannii leaf extract. Indian J Sci Technol 2012;5:1885-7.

10. Ganguly M, Devi N, Mahanta R, Borthakur MK. Effect of Mimosa pudica root extract on vaginal oestrous and serum hormones for the screening of antifertility activity in albino mice. Contracept 2007;76:482-5.

11. Venkateshwarlu G, Vijayabhaskar K, Pavankumar G, Kiran Kumar P, Harishbabu K, Malothu R. Wound healing activity of Mimosa Pudica in albino Wistar rats. J Chem Pharm Res 2011;3:56-60.

12. Joseph B, George J, Mohan J. Pharmacology and traditional uses of Mimosa pudica. Int J Pharm Sci Drug Res 2013;5:4.

13. Coimbra A, Magnanini A. Considerations sobre Mimosa pudica no combate a arosao superficial. Anucio Braz Econ Floresta Inst Nac Pinho Braz; 1953. p. 131-6.

14. Bhakuni DS, Dhar ML, Dhar MM, Dhawan BN, Mehrotra BN. Screening of Indian plants for biological activity. Indian J Exp Biol 1969; 7:250-62.

15. Zaware BB, Chaudhari S, Shinde MT. An overview of Mimosa pudica Linn. chemistry and pharmacological profile. Res J Pharm Biol Chem Sci 2014;5:757-61.

16. Uehlein N, Kaldenhoff R. Aquaporins and plant leaf movements. Ann Bot 2008;101:1-4.

17. Yao $\mathrm{H}, \mathrm{Xu} \mathrm{Q}$, Yuan $\mathrm{M}$. Actin dynamics mediate the changes of calcium level during the pulvinus movement of Mimosa pudica. Plant Signal Behav 2008;3:954-60.

18. Patro G, Kumar Bhattamisra S, Kumar Mohanty B. Effects of Mimosa pudica L. leaves extract on anxiety, depression and memory. Avicenna J Phytomed 2016;6:696-710.

19. Varnika S, Ashish S, Imran A. A review on ethnomedical and traditional uses of Mimosa pudica. Int Res J Pharm 2012;3:41-4.

20. Bendgude RD, Maniyar MG, Kondawar MS, Patil SB, Hirave RV. The anti-helminthic activity of leaves of Mimosa pudica. Int Institutional Pharm Life Sci 2012;2:120-5.

21. Pratap Chandra, Deepak V, Sai Krishna, Saniya Fathima, Ameena Thaha, Jeenitha Raj. Analysis of phytochemical constituents and anthelmintic activity of leaf extracts of Mimosa pudica L. Asian J Biomed Pharm Sci 2018;8:2249-622.

22. Azmi L, Manish KS, Ali Kamal A. Pharmacological and biological overview on Mimosa pudica linn. Int J Pharm Life Sci 2011;2:1226-34.

23. Ayan Purkayastha, Pinuki Chakravarty, Babul Dewan. Evaluation of hepatoprotective activity of the ethanolic extract of leaves of Mimosa pudica linn in carbon tetrachloride-induced hepatic injury in albino rats. Int J Basic Clin Pharmacol 2016;5:496-501.

24. Kokane DD, More RY, Kale MB, Nehete MN, Mehendale PC, Gadgoli $\mathrm{CH}$. Evaluation of wound healing activity of root of Mimosa pudica. J Ethnopharmacol 2009;124:311-5.

25. Jagetia GC, Lyngdoh R, Lalramchuana, Borah BK. Mimosa pudica (Lajwanti) accelerates repair and regeneration of deep dermal excision wound in swiss albino mice. Int J Complement Alt Med 2017;9:00293.
26. Hindmarch I. Expanding the horizons of depression: beyond the monoamine hypothesis. Hum Psychopharmacol 2001;16:203-18.

27. Molina M, Contreras CM, Tellez-Alcantara P. Mimosa pudica may possess antidepressant actions in the rat. Int J Phytother Phytopharm 1999;6:319-23.

28. Irfan Sajid, Bijan Kumar Karmaker, Zamiul R, Islam MM, M Ekramul H. CNS depressant and antinociceptive activities of the aerial parts of Mimosa pudica. Eur J Appl Sci 2013;5:127-33.

29. Takagi K, Watanabe M, Saito H. Studies of the spontaneous movement of animals by the hole cross test; effect of 2dimethylaminoethanol and its acyl esters on the central nervous system. Japan J Pharmacol 1971;21:797-810.

30. Robert H, Howland M. General health, health care utilisation, and medical comorbidity in dysthymia. Int J Psychiatry Med 1993;23:211-38.

31. Bum EN, Soudi S, Ayissi ER, Dong C, Lakoulo NH, Maidawa F, et al. Anxiolytic activity evaluation of four medicinal plants from cameroon. Afr J Tradit Complement Altern Med 2011;8:130-9.

32. Sarris J, Panossian A, Schweitzer I, Stough C, Scholey A. Herbal medicine for depression, anxiety and insomnia: a review of psychopharmacology and clinical evidence. Eur Neuropsychopharmacol J Eur Coll Neuropsychopharmacol 2011;21:841-60.

33. Sowmya A, Ananthi T. Hypolipidemic activity of Mimosa pudica linn on butter induced hyperlipidemia in rats. Asian J Res Pharm Sci 2011;1:123-6.

34. Yupparach P, Konsue A. Hypoglycemic and hypolipidemic activities of ethanolic extract from Mimosa pudica L. in normal and streptozotocin-induced diabetic rats. Pharmacog J 2017;9:834-7.

35. Sia F, Vejayan J, Jamuna A, Ambu S. Efficacy of tannins from Mimosa pudica and tannic acid in neutralising cobra (Najakaouthia) venom. J Venom Anim Toxins Trop Dis 2011;17:42-8.

36. Elango V, Carolin Oliver Raghu PS. Antiulcer activity of the leaf ethanolic extract of Mimosa pudica in Rats. Hygeia J D Med 2012;4:34-40.

37. Vinothapooshan G, Sundar K. Anti-ulcer activity of Mimosa pudica leaves against gastric ulcer in rats. Res J Pharm Biol Chem Sci 2010;1:606-14.

38. Goli V, Bhaskar KV, Macharla SP, Jimmidi Bhaskar, Devi PS, Ramchander T. Effects of anti-Inflammatory activity of Mimosa pudica. Asian J Pharm Res 2011;1:69-71.

39. Nair PV, Bindu Latha RN. Anti-inflammatory activity of hydroalcoholic extract of Mimosa pudica whole plant in rats. Int J Basic Clin Pharmacol 2017;6:518-22.

40. Yupparach P, Konsue A. Hypoglycemic and hypolipidemic activities of ethanolic extract from Mimosa pudica L. in normal and Streptozotocin-induced diabetic rats. Pharmacogn J 2017;9:834-7.

41. Tamilarasi T, Ananthi T. Phytochemical analysis and antimicrobial activity of Mimosa pudica Linn. Res J Chem Sci 2012;2:72-4.

42. Chukwu O, Ahuchaogu A, Ukaogo P, Obike A, Echeme J. Antifungal activity of Mimosa pudica, isolation and NMR characterization of bioactive components. Asian J Chem Sci 2017;2:1-5

43. Rajalakshmi K, N Banu. Antimicrobial activity of natural chlorophyllin from endangered medicinal plant Mimosa Pudica L. Int J Pharm Pharc Sci 2016;8:387-9.

44. Mahesh AG, Jayadevappa H, Mahadevan KM, Shastry RA, Habbu $\mathrm{PV}$, Sayeswara HA. Isolation and characterisation of secondary metabolite from Habenaria intermedia D. Don for screening of hepatoprotective potential against carbon tetrachloride induced toxicity in albino rat liver. Int J Curr Pharm Res 2014; 7:57-61. 